\title{
Peer Assessment in Facebook Comment Column about One Topic in Writing II Subject of the Fourth Semester Students of Sriwijaya University English Study Program
}

\author{
Rita Inderawati, Ahmad Hafiz Pratama, Bambang A. Loeneto \\ Sriwijaya University, Indonesia \\ ritarudisaid@yahoo.com
}

\begin{abstract}
The objectives of this study were to find out (1) the completeness of the students' comments on Facebook, (2) the quality of the students' comments, and (3) the percentage of how well the students identified the characters of a good paragraph. The population of this study was the fourth-semester Palembang class students of English Education Study Program 2013 of Sriwijaya University. The sample of the study was 48 students that were selected by using total sampling technique. The data were collected from the students' comments on Facebook of Writing II class in the academic year 2015 and analyzed by using two rubrics containing scoring systems. The results showed that the completeness in giving comments on the Facebook group could be categorized into a very good category with the final score was 10 . While, the quality of the comment from the students was also Good with the final score was 15.56. The percentage of how well the students identified the characters of a good paragraph was $83.33 \%$ in very good level, $10.41 \%$ in good level and $6.25 \%$ in average level. Overall, the final score of the students' comments from those three research questions were average with the score was 9.85. It can be concluded that the students' comments on Facebook Comment Column in Writing II Class in the academic year 2015 was average.
\end{abstract}

Keywords: academic writing; Facebook; peer comments

\section{INTRODUCTION}

Language plays an important role in human life since it is a tool which humans use to interact with other people. We as a human being, of course, use language to interact with other people to understand each other. The importance of language is essential to every aspect and interaction in our everyday lives. We use language to inform the people

ENGLISH FRANCA : Academic Journal of English Language and Education Vol. 2, No. 1, 2018, STAIN Curup

P-ISSN 2580-3670, E-ISSN 2580-3689 
around us of what we feel, what we desire, and question/understand the world around us. We communicate effectively with our words, gestures, and tone of voice in a multitude of situation. English is known as a global language. English as a bridge of communication in the world has a big influence on the social life. Nowadays, without English, it is rather difficult for someone to step forward, looking for another chance to have a good life. Moreover, English is being the most necessary requirement to get into the higher level of bright future, especially for career development. It means that by mastering English, users are able to get several benefits as a well-prepared people. The government of Indonesia acknowledges English as a compulsory subject in the daily life of education for the students of many levels. Based on Indonesian Government Regulation, No. 28, 1990, English is one of the compulsory subjects which is taught from the first year of the junior high school to the University level. There are four kinds of English skill, one of that is writing. Writing is one of the important skills which should be learned and mastered by students. Writing is a socio-cognitive activity that involves skills in planning and drafting, as well as knowledge of language, contexts, and audiences (Hyland, 2007). Writing becomes very important because it is the highest skill in language learning that people should master. Writing ability is the ability to express ideas, opinions and thoughts and a way of communicating information, ideas, and feeling to other people. In fact, writing is a way of communication used by the writer to express, to generate, develop and organize the ideas for the reader by using the graphic in a certain language. Harmer (2004, p.3) states that writing is a comprehensive ability involving grammar, vocabulary, and other elements; it has anything to do with listening, speaking, and reading.

There were three writing courses in Faculty of Teacher Training and Education that students learnt for the academic year 2013 of English Education Study Program of Sriwijaya University; Writing I, Writing II, and Writing III. In Writing I subject the students were introduced to the definition of writing, the concept of writing, and all of the beginning of writing process. Writing II subject has concerned with the process of making a paragraph in academic writing. And last, Writing III subject deals with making an essay of academic writing. The teaching of writing can be applied in many ways; one of them is by using Facebook. Facebook is a ubiquitous technology for social use by students rather than an academic networking platform for their courses (Rambe, 2010). Wichadee $(2013$, p. 3 ) also states that it would be beneficial to use Facebook as a platform for students to give and get feedback since it 
creates authentic language interaction, increases students' motivation and enhances their English learning achievement. In writing II class, Facebook was used as a medium for teaching and learning activities. Facebook was chosen because it has many features which help students in learning process. One of the features of Facebook was a group. That group belonged to the 2013 Palembang students. The name of that group is Writing II with RI Palembang 2015. There were some materials that had been discussed in it, such as: making a paragraph about Facebook, observing the facilities in Sriwijaya University, commenting on a book that could be found in the library, giving reasons why English as a major was selected, making a paragraph about mother and her hobbies, creating a paragraph about Writing II class and its interesting activities, and telling about the lecturer, and last the students had final exam. In addition, they could give comment to each other in that group as a learning process of writing. They should read the topic first, think about it, and if there was something that they wanted to give comment, they could do it in comment column. Cheung, et al (2011) had noted that while "commenting in their Facebook, the students developed confidence in writing and reading English and communicating with other users of Facebook." Additionally, it also gives them an opportunity to enhance their knowledge about the text review. Through commenting, students can state their opinion, make an argument, thus it will lead them to write their own review text.

Oshima and Hogue (1999, p. 3) and Harmer (2007, p. 4) mention there are four main stages in the writing process: planning, drafting, editing, and writing a final revision. Planning is the beginning stage where the writer must determine what he or she should write. Spring (1999) states that planning is really a matter of making choices about what people will include in the essay, how they will say it, why they are saying it, how they want the reader to react, and what they want to happen after the reader has read their work. A draft refers to the first version of a piece of writing. The drafting stage is characterized by increasingly less tentative efforts toward implementing a specific plan for written communication. Spring (1999) explains that draft reminds the writer that the first copy of any piece of writing is only a first attempt which needs considerable fine-tuning. The editing stage involves the identification and correction of factual errors, deletion or revision of tangential issues, and rectification of omissions in a written document. Therefore, Winter $(1999$, p. 5) states that in editing process the focus in the surface of the writing, the appropriate word choice and correct format, spelling, grammar usage, and punctuation. In revising, 
strive for vivid and concrete details, use synonyms (use a thesaurus and a dictionary), combine related ideas, vary sentence length, and move ideas if it would improve the message (Spring, 1999). When the writer edits his or her draft and makes changes, they produce their final version. This final version may look very different with both the original copy and the first draft because it has been changed in the editing process.

Furthermore, related to this, there are two kinds of assessment, self-assessment and peer assessment. Andrade and Du (2007, p. 160) put forward that self-assessment is a process of formative assessment during which students reflect on and evaluate the quality of their work and their learning, judge the degree to which they reflect explicitly stated goals or criteria, identify strengths and weaknesses in their work, and revise accordingly. While McMillan and Hearn (2008) mention that self-assessment could mean that students simply check off answers ona multiple-choice test and grade themselves, but it involves much more than that. Self-assessment is more accurately defined as a process by which students: 1) monitor and evaluate the quality of their thinking and behavior when learning and 2) identify strategies that improve their understanding and skills. On the other hand, peer assessment requires students to provide either feedback or grades (or both) to their peers on a product or a performance, based on the criteria of excellence for that product or event which students may have been involved in determining (Falchikov, 2007, p. 132). Students can help each other to make sense of the gaps in their learning and understanding and to get a more sophisticated grasp of the learning process. Students receiving feedback from their peers can get a wider range of ideas about their work to promote development and improvement. Peer assessment can also encourage collaborative learning through interchange about what constitutes good work. This study is a concern with peer assessment because generally the writer will check and analyze the comment from others as an analyzing process.

In the Facebook group, the lecturer listed some requirements for peer assessment. There were 11 requirements for giving a good comment: (1) the reviewer should comment on the title, (2) the reviewer should comment on the topic sentence, (3) the reviewer should comment whether the topic sentence has a controlling idea or not, (4) the reviewer should comment on the concluding sentence, (5) the reviewer should comment whether the concluding sentence begins with an appropriate end of paragraph signal or not, (6) the reviewer 
should comment whether the concluding sentence tells the reader the things mention in controlling idea or not, (7) the reviewer should comment if there are any unclear sentences or not, (8) the reviewer should suggest the writer a way to improve the unclear sentences, (9) the reviewer should comment whether the paragraph have good unity or not, (10) the reviewer should comment whether the paragraph has good coherence or not and (11) the reviewer should comment if there are some errors in grammar and mechanics. The reviewer refers to the students who joined the online class on Facebook. Similar to this, Hattie and Timperley (2007, p. 104) state that to be effective, feedback needs to be clear, purposeful, meaningful, and compatible with students" prior knowledge and to provide logical connections. They put forwards six characteristics of effective feedback, they are (1) task specific. Feedback requires learning context and therefore needs to be task specific. There is no advantage to tangential conversations when providing feedback, (2) self-regulation. Feedback should encourage the learner's selfregulation by enhancing self-efficacy and self-esteem. This concept corresponds with teaching learners how to learn, (3) low task complexity. Feedback should address tasks of low complexity. Goals should be broken down into manageable tasks, as this increases the effectiveness of feedback, (4) timing. The timing of feedback is not as straightforward as some may think. Quick turn around on the correctness of simple tasks benefits students. While students may prefer instantaneous feedback, the literature supports that task process feedback benefits from a delay where students have time to think about difficult tasks before receiving the feedback, (5) praise. The most prevalent and least effective, praise disrupts the positive effects of feedback. It should be used cautiously, as students tend to enjoy private praise though it fails the need for task specificity and (6) technology enhanced. Used appropriately, technology has the ability to provide timely feedback, improve collaboration, increase social presence, increase dialogue, improve reflection, support learning principles, and increase student satisfaction. Considering to use the technologies available at schools can optimize technology in providing students' feedback.

However, there were some related studies which are considered closely related to this study. The first study entitled "Grammatical Error Analysis of Students Comment Writing Based on Facebook Game in English Intensive Class of STAIN Jurai Siwo Metro" was conducted by Dedy Subandowo in 2013. The research showed that the grammatical errors made by the students in English intensive class were redundant 
use of auxiliary, unfamiliar words, nominal or verbal sentence, and making the error of interrogative form pattern. The second study entitled "Critical Discourse Analysis of Collaborative Engagement in Facebook Posting" was conducted by Patient Rambe in 2012. The findings suggest the prevalence of formal authoritative (or hierarchical) discourses, few informal liberating (horizontal) discourses, nascent peer-based collaboration and limited learner engagement with theory. And the last study entitled "The Implementation of Peer Editing Technique to Improve Students" Writing Achievement" was conducted by Fajri, Inderawati, and Mirizon in 2015. The result of paired sample ttest in experimental group showed the t-obtained was higher than the critical value of $t$-table $(9.087>2.041)$. It could be stated that there was a significant difference in the recount writing achievement before and after the treatment in the experimental group. In addition, the independent sample t-test showed the t-obtained was also higher than ttable after students" mean score was calculated (8.474 > 2.003). It can be concluded that there was a significant difference in recount writing achievement between the students who were taught through Peer editing Technique (experimental group) and those who were not (control group). In brief, Peer editing Technique was effective in writing achievement. However, this current study elaborated the completeness and quality of the peer assessment to show their critical thinking in commenting on their peer's writing. Therefore, the writer was interested in conducting this research in order to find out how the effectiveness of Writing II subject to the fourth-semester students English Education Study Program in Faculty of Teacher Training and Education of Palembang class Sriwijaya University with Rita Inderawati 2015.

In line with the explanation above, this study focused on conducting the descriptive study to describe, to present and to conclude that the writer got through the analysis process. This study was aimed to answer this following research questions: (1) how was the completeness of the 2013 students of English Education in giving comment in Facebook of group writing II with RI Palembang 2015 be categorized? (2) how was the quality of the comments of the 2013 students of English Education study program? (3) how well did the students identify the characteristics of a good paragraph?

\section{RESEARCH METHOD}

This study was conducted by employing the descriptive method. This method was meant to describe the collected data in form of the 
completeness of the comments from the students, the quality of the comments from the students and the percentage of how well the students identified the characteristics of a good paragraph from the fourth-semester students Palembang class of English Education study program 2013. The population of this study was all the fourth-semester students Palembang class of English Education Study Program 2013 in Faculty of Teacher Training and Education. The number of population was 48 students. In this study, the writer took the sample from the total number of the population by employing total sampling technique.In collecting the data for this study, the writer collected the comments from the students in the Facebook group of writing II with RI Palembang 2015. Then, the writer analyzed those comments used two kinds of rubric. According to Mertler (2001), rubrics are rating scales as opposed to a checklist that is used with performance assessments. Both of the rubrics were developed by Rita Inderawati from Sriwijaya University. The first rubric entitled rubric for commenting a single academic paragraph writing and the second rubric entitled rubric for academic paragraph writing. Then for checking the reliability of the comments from the students the writer used inter-rater reliability to find out the reliability of the students" comments by involved two raters. Phelan and Wren (2005) state that inter-rater reliability is a measure of reliability used to assess the degree to which different judges or raters agree in their assessment decisions. The raters were chosen based on some criteria: they are those who already hold a master degree and have more than 5-years teaching experiences. The raters helped the writer to check the quality of the comments by using the rubric for academic paragraph writing.

In this study, the data were analyzed by checking the student"s responses toward the eleven questions of a complete comment and the scores were calculated using Microsoft Excel 2010. The writer used symbol " $\sqrt{ }$ " if the student completed the aspect and symbol "-" was meant to be as did not complete. There were four scores based on the total responses that the students did, they were: score D (bad) consists of $0-2$ responses, score $C$ (average) consists of $3-5$ responses, score $B$ (good) consists of $6-8$ responses and score A (very good) consists of 9 - 11 responses. For each response, it was given one point. It means that one response had one point. For example, if 9 responses were given the student got 9 or the score was 9. The biggest score in giving the responses was 11 while the lowest score was 0 . The research question number two was analyzed by using Rubric for Academic Paragraph Writing and the scores were calculated by using Microsoft Excel 2010. 
The comments would be analyzed by the raters. There are four scores in that rubric, they are: score 1 (bad), score 2 (average), score 3 (good) and score 4 (very good). There are also 6 aspects of an academic paragraph writing, they are (1) Organization, (2) Supporting Sentences, (3) Concluding Sentence, (4) Unity, (5) Coherence and (6) Use of Language. So, the biggest possible score that the students got was 24 and the lowest score was 6 . Each score had its own score range. For score 4 (very good) it had the scoring range $19-24$. For score 3 (good) it had the scoring range $13-18$. For score 2 (average) it had the scoring range $7-12$ and for score 1 (bad) it had the scoring range $1-6$. The research question number three was analyzed by using the table to check how well the students identified a good paragraph. In the table, there were five aspects of a good paragraph, they are (1) Topic Sentence, (2) Supporting Sentence, (3) Concluding Sentence, (4) Unity and Coherence.

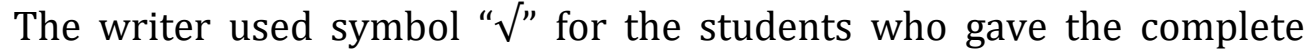
comment for every aspect, and symbol " $\mathrm{x}$ " for the students who didn't give the complete comment for every aspect. The biggest score that the students got was score 5 and the lowest score that the students got was score 1 . The complete comment means that the students had already identified the characteristics of a good paragraph well and the incomplete comment means that the students did not already identify the characteristics of good paragraph well. Then, the writer categorized it into five categories based on the total aspects that the students did, they were: score 5 (very good) that contained 5 aspects, score 4 (good) that contained 4 aspects, score 3 (average) that contained 3 aspects, score 2 (bad) that contained 2 aspects and score 1 (failed) that contained 1 aspects.

\section{FINDINGS AND INTERPRETATION OF THE STUDY}

\section{The Completeness of the Comments from the Students}

The result of the analysis process of the completeness of the comments from the students showed that: There were 4 students giving 9 responses, 38 students giving 10 responses and 6 students giving 11 responses. So, there were three scores: 9, 10 and 11.

Table 1

The Students' Responses

\begin{tabular}{|c|c|c|c|}
\hline $\begin{array}{c}\text { Range of Score } \\
\text { Category }\end{array}$ & $\begin{array}{c}\text { Number of } \\
\text { Students }\end{array}$ & $\begin{array}{c}\text { Number of } \\
\text { Responses }\end{array}$ & Score \\
\hline Very Good $(9-11)$ & 4 & 9 & 9 \\
\cline { 2 - 4 } & 38 & 10 & 10 \\
\hline
\end{tabular}




\begin{tabular}{|c|c|c|c|}
\hline & 6 & 11 & 11 \\
\hline Good (6-8) & 0 & 0 & 0 \\
\hline Average (3-5) & 0 & 0 & 0 \\
\hline Bad (0-2) & 0 & 0 & 0 \\
\hline
\end{tabular}

Table 2

The Average Score of Students Responses

\begin{tabular}{|c|c|c|}
\hline & Score & $\begin{array}{c}\text { Number of } \\
\text { Students }\end{array}$ \\
\hline & 9 & 4 \\
\hline & 10 & 38 \\
\hline & 11 & 6 \\
\hline Sum & 30 & 48 \\
\hline Average & 10 & \\
\hline
\end{tabular}

From the writer"s results obtained by using Microsoft Excel 2010, the average score of students" responses was 10. Score 10 was included into a very good category with the range of score $9-11$. Finally, the writer could conclude that the completeness of the comment of the 2013 students of English Education Study Program was very good.

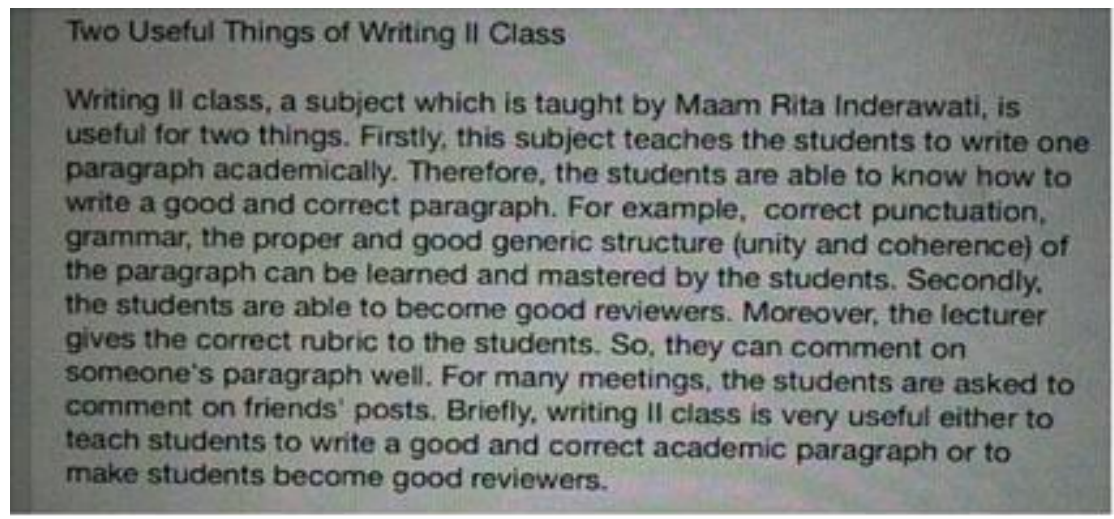

\section{Example 1}

Paragraph from the Lecturer

The examples of the comments from the students who got score 9, 10 and 11. 


\section{Student 1}

The paragraph which has already made, has fulfolled the reguirements in academic writing First, the title is correct because it has written with the form of a phrase. "Two Useful Thing: of Writing II Class". Second, the topic sentence was clear. Third, the topic sentence already have controlling idea, the controlling idea is " is useful for two things:. Fourth the paragraph has a concluding sentence, it is "Briefly, Writing II Class is very useful for either to teach students to write a good and correct academic paragraph or to make students become good reviewers". Fifth, the concluding sentence has already told the readers about the things mention in controlling idea, it is " is very useful for either to teach students to write a good and correct academic paragraph of to make students become good reviewers": Sixth, In the paragraph there are no unclear sentences and the paragraph has a good unity because it feets one main idea, useful for two things . Seventh. the paragraph has a good coherence because it uses the correct transition signals like firstly. therefore, and moreover. The last, here is no errors in grammar and mechanics because the paragraph have been checked the spelling and grammar in the computer. In conclusion, the paragraph is good.

\section{Student 2}

The single academic paragraph writing of this paragraph has completed of ten requirements. The title is correct because it is already in a form of phrase. The topic sentence is also correct because it is already clear and also written with controlling idea. There is a good enough concluding sentence which it begins with appropriate end of signal "Breifly... This paragraph has good unity because it only tells about two main things. Beside that, it also has good coherence. Because it uses many and correct transition signal " firstly... secondly... There is a concluding sentence tell the reader the things mention in controlling idea like and.... to... And this is a clear sentence, then there is no any errors in grammar and mechanics (spelling, punctuation, and capitalization). In short, this paragraph above has already fulfilled of ten requirements for a good single academic paragraph.

5. Mel 2015-Disunting - Suka - O 1- Lainya

\section{(Score 9)}

\section{Student 3}

The Single Paragraph and its Ten Requirements The paragraph has met all of the ten requirements of single academic paragraph. Firstly, the first requirement is a title. The title of this single paragraph is "Two Useful of Writing III. According to the requirement, the title is good enough because it use a phrase form not a sentence form. Next, the second and third requirements are topic sentence and controlling idea. The topic sentence of this paragraph is "Writing II Class" which is correct because it is agree with the title. The controlling idea is "..is useful for two things", it is also correct but the controlling idea would be nicer if it is changed into "gives two useful things". Then the fourth, fifth, and sixth requirements are about a concluding sentence. There is already a concluding sentence in the last sentence of this paragraph. It is "Briefly, Writing II Class is very useful either to teach students to make a good and correct paragraph or to make students become good reviewers." This concluding sentence begins with an appropriate end of paragraph signat, it is "Briefly". It also tells two things which have been mentioned in the controlling idea. Next, the seventh requirement is about uncleat sentence. I think there is no unclear sentence in this paragraph because all of the sentences are already clear and it is easy to read and understand. Then, the eighth requirement is a good unity. This simple paragraph already has a good unity because it only tells about two useful things of Writing II Class. The ninth

useful things of Writing II Class. The ninth requirement is a good coherence. I think this paragraph has a good coherence because it uses some transition signals. The last requirement is grammar and mechanics. I think there is no error in grammar and mechanics. In brief, this paragraph has met the ten requirements of single academic paragraph. 
For score 9 it showed that: first, the student commented on the title of the paragraph "the title is correct because it has written with the form of a phrase, "Two Useful Things of Writing II Class". Second, the student commented on the topic sentence "the topic sentence was clear". Third, the student commented that the topic sentence has a controlling idea "the topic sentence already have a controlling idea, the controlling idea is "is used for two things". Fourth, the student commented on the concluding sentence "the paragraph has a concluding sentence, it is "Briefly, Writing II class is very useful for either to teach students to write a good and correct academic paragraph or to make students become good reviewers". Fifth, the student did not comment that the concluding sentence begins with an appropriate end of paragraph signal. Sixth, the student commented that the concluding sentence tells the reader the things mention in controlling idea "the concluding sentence has already told the readers about the things mention in controlling idea, it is "is very useful for either to teach students to write a good and correct academic paragraph or to make students become good reviewers". Seventh, the student commented if there are any unclear sentences "in the paragraph there are no unclear sentences". Eighth, the student did not suggest a way to improve the unclear sentences. Ninth, the student commented that the paragraph has good unity "the paragraph has a good unity because it feels one main idea, useful for two things". Tenth, the student commented that the paragraph has good coherence "the paragraph has a good coherence because it uses the correct transition signals like firstly, therefore, and moreover". Eleventh, the student commented if there are any errors in grammar and mechanics "here is no errors in grammar and mechanics because the paragraph have been checked the spelling and grammar on the computer".

For score 10 it showed that: first, the student commented on the title of the paragraph "the title is correct because it is already in a form of the phrase". Second and third, the student commented on the topic sentence and also commented that the topic sentence has a controlling idea "the topic sentence is also correct because it is already clear and also written with controlling idea". Fourth and fifth, the student commented on the concluding sentence and also commented that the concluding sentence begins with an appropriate end of paragraph signal "there is a good enough concluding sentence which it begins with the appropriate end of signal "Briefly...". Sixth, the student commented that the concluding sentence tells the reader the things mention in controlling idea "there is a concluding sentence tell the reader the things mention in controlling idea like "and... to...". Seventh, the student commented if 
there are any unclear sentences "this is a clear sentence". Eighth, the student did not suggest a way to improve the unclear sentences. Ninth, the student commented that the paragraph has good unity "this paragraph has good unity because it only tells about two main things". Tenth, the student commented that the paragraph has good coherence "is also has good coherence because it uses many and correct transitions signal "firstly...secondly...". Eleventh, the student commented if there are any errors in grammar and mechanics "there is no any errors in grammar and mechanics (spelling, punctuation, and capitalization)".

For score 11 it showed that: first, the student commented on the title of the paragraph "the title of this single paragraph is "Two Useful of Writing II". The title is good enough because it uses a phrase form, not a sentence form". Second and third, the student commented on the topic sentence and also commented that the topic sentence has a controlling idea "the topic sentence of this paragraph is "Writing II Class" which is correct because it agrees with the title. The controlling idea is "..is useful for two things", it also correct but the controlling idea would be nicer if it is changed into "gives two useful things". Fourth, the student commented on the concluding sentence "there is already a concluding sentence in the last sentence of this paragraph. It is "Briefly, Writing II class is very useful for either to teach students to write a good and correct academic paragraph or to make students become good reviewers". Fifth, the student commented that the concluding sentence begins with an appropriate end of paragraph signal "this concluding sentence begins with an appropriate end of paragraph signal, it is "Briefly". Seventh and eighth, the student commented if there are any unclear sentences and gave the explanation about the unclear sentence "I think there is no unclear sentence in this paragraph because all of the sentences are already clear and it is easy to read and understand". Ninth, the student commented that the paragraph has good unity "this simple paragraph already has a good unity because it only tells about two useful things of Writing II class". Tenth, the student commented that the paragraph has good coherence "I think this paragraph has a good coherence because it uses some transition signals". Eleventh, the student commented if there are any errors in grammar and mechanics "I think there is no error in grammar and mechanics".

\section{The Quality of the Comments from the Students}

The results of analysis process from the raters used the rubric for academic paragraph writing showed that: 
From rater 1 , there were 2 students getting score 12,1 student getting score 14, 3 students getting score 15, 2 students getting score 16, 6 students getting score 17, 10 students getting score 18 and 24 students getting score 19 from the total 48 students. From rater 2, there was 1 student getting score 11, 1 student getting score 12, 1 student getting score 14, 4 students getting score 15, 3 students getting score 16, 4 students getting score 17, 11 students getting score 18 and 23 students getting score 19 from the total 48 students. The average from both raters can be seen in this following table:

Table 3

Table of Average (Rater 1 )

\begin{tabular}{|c|c|c|c|}
\hline & No & Score & $\begin{array}{c}\text { Number of } \\
\text { Students }\end{array}$ \\
\hline & 1 & 12 & 2 \\
\hline & 2 & 14 & 1 \\
\hline & 3 & 15 & 3 \\
\hline & 4 & 16 & 2 \\
\hline & 5 & 17 & 6 \\
\hline & 6 & 18 & 10 \\
\hline & 7 & 19 & 24 \\
\hline Sum & & 111 & 48 \\
\hline Average & & 15.86 & \\
\hline
\end{tabular}

Table 4

Total of Average (Rater 2)

\begin{tabular}{|c|c|c|c|}
\hline & No & Score & $\begin{array}{c}\text { Number of } \\
\text { Students }\end{array}$ \\
\hline & 1 & 11 & 1 \\
\hline & 2 & 12 & 1 \\
\hline & 3 & 14 & 1 \\
\hline & 4 & 15 & 4 \\
\hline & 5 & 16 & 3 \\
\hline & 6 & 17 & 4 \\
\hline & 7 & 18 & 11 \\
\hline & 8 & 19 & 23 \\
\hline Sum & & 122 & 48 \\
\hline Average & & 15.25 & \\
\hline
\end{tabular}


Table 5

Average from Both Raters

\begin{tabular}{|c|c|}
\hline & Score \\
\hline Rater 1 & 15.86 \\
\hline Rater 2 & 15.25 \\
\hline Average & 15.56 \\
\hline
\end{tabular}

From the writer"s results obtained by using Microsoft Excel 2010, the result from rater 1 showed the average score was $\mathbf{1 5 . 8 6}$ and from rater 2 showed the average score was 15.25. The average score from both raters showed the score was $\mathbf{1 5 . 5 6}$. Score 15.56 was included into a good category with the scoring scale $13-18$. Finally, the writer could conclude that the quality of the comment of the 2013 students of English Education study program was good.

The Percentage of How Well the Students Identify the Characteristics of a Good Paragraph

The results of analysis process showed that: 40 students got score 5 (very good), 5 students got score 4 (good), and 3 students got score 3 (average). There were no results found for score 2 (bad) and score 1 (failed). The result of this analysis process can be seen in this following table:

Table 6

Total of Students" Aspects

\begin{tabular}{|c|c|c|c|c|}
\hline No & Score & Total of the Aspects & Category & Total \\
\hline 1 & Score 5 & 5 Aspects & Very Good & 40 students \\
\hline 2 & Score 4 & 4 Aspects & Good & 5 students \\
\hline 3 & Score 3 & 3 Aspects & Average & 3 students \\
\hline 4 & Score 2 & 2 Aspects & Bad & 0 students \\
\hline 5 & Score 1 & 1 Aspect & Failed & 0 students \\
\hline
\end{tabular}

Those five aspects of a good paragraph are (1) Topic Sentence, (2) Supporting Sentence, (3) Concluding Sentence, (4) Unity and (5) Coherence. 


\section{Student 1}

Here I would like to give comments to the rubric. The rubric has already mentioned ten requirements in academic writing. First of all, the title of this rubric is correct because it matches to the paragraph. Second, this good rubric also has clear topic sentence which is interesting to read and to understand. Third, the controlling idea is noticed to the rubric, "useful for two things". Fourth, it consists of concluding sentence, too for example in this rubric, "briefly", Fifth, the rubric has exactly a concluding sentence with an appropriate end. Sixth, the concluding sentence here tells the readers about the controlling idea which is talked about two things and makes sense. Seventh, for this point, there is no unclear sentence. Eight, ninth, and tenth, this great rubric has a good unity, good coherence with each sentence in the paragraph, and finally 1 would like to say there is no error in its grammar.

6 Mei 2015 - Suka - Lainnya

(Score 3)

\section{Student 2}

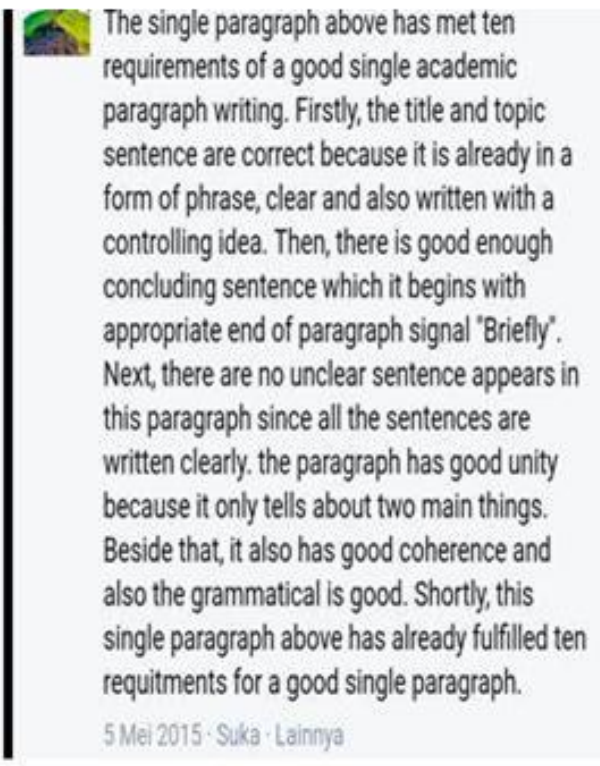

(Score 4)

\section{Student 3}

The paragraph provided by Maam Rita Inderawati is regarded as a good academic paragraph due to it's completeness according to the ten rubrics of Oshima and Hogue. Firstly, the title is written correctly because it tells the main contents of the paragraph well. The topic sentence of the paragraph is also correct because it describes the topic of the paragraph perfectly, but I think it would be nicer if the words "which is" from the sentence "the subject which is taught by Maam Rita Inderawati" are omitted. The next is the controlling idea, it is written very well and does not need any correction. The next aspect is the concluding sentence, the concluding sentence is good because it begins with an appropriate end of paragraph signal. The concluding sentence has also mentioned the things that had been explained in advance. Then, the paragraph has no unclear sentences. After that, the aspect of unity of this paragraph is written very well because the paragraph focuses on one main idea and does not go out of the track. Next, the paragraph has a good coherence because the paragraph consist of many transition signals.
Finally, the last aspect is the grammatical and mechanics, there are no mistakes found regarding to the spelling, punctuation or capitalization. According to the ten requirements of a good academic paragraph from Oshima and Hogue's rubrics that was used in checking the paragraph, it can be concluded that the paragraph provided by Maam Rita Inderawati can be considered as a good academic paragraph. 5 Mei 2015-Suka - Lainnya

(Score 5)

\section{Example 2}

The Comments from the Students 
For score 3 it showed that: first, the student identified the topic sentence of the paragraph well "this good rubric also has a clear topic sentence which is interesting to read and to understand". Second, the student identified the supporting sentence of the paragraph well "First of all, the title of this rubric is correct because it matches the paragraph. Second, this good rubric also has a clear topic sentence which is interesting to read and to understand. Third, the controlling idea is noticed to the rubric, "useful for two things". Fourth, it consists of concluding the sentence, too for example in this rubric, "briefly". Fifth, the rubric has exactly a concluding sentence with an appropriate end. Sixth, the concluding sentence here tells the readers about the controlling idea which is talked about two things and makes senses. Seventh, for this point, there is no unclear sentence. Eighth, ninth, and tenth, this great rubric has a good unity, good coherence with each sentence in the paragraph, and finally, I would like to sat there is no error in its grammar". Third, the student identified the concluding sentence of the paragraph well "it consists of concluding the sentence, too for the example in this rubric, "briefly". The rubric has exactly a concluding sentence with an appropriate end. The concluding sentence here tells the readers about the controlling idea which is talked about two things and makes sense". Fourth and fifth, the student did not identify the unity and the coherence of the paragraph well.

For score 4 it showed that: first, the student identified the topic sentence of the paragraph well "the title and the topic sentence are correct because it is already in a form of a phrase, clear and also written with a controlling idea". Second, the student identified the supporting sentence of the paragraph well "Firstly, the title and the topic sentence are correct because it is already in a form of a phrase, clear and also written with a controlling idea. Then, there is good enough concluding sentence which it begins with the appropriate end of paragraph signal "Briefly". Next, there is no unclear sentence appears in this paragraph since all the sentences are written clearly. The paragraph has good unity because it only tells about two main things. Besides, it also has good coherence and also the grammatical is good". Third, the student identified the concluding sentence of the paragraph well "then, there is good enough concluding sentence which it begins with the appropriate end of paragraph signal "Briefly". Fourth, the student identified the unity of the paragraph well "the paragraph has good unity because it only tells about two main things". Fifth, the student did not identify the coherence of the paragraph well. 
For score 5 it showed that: first, the student identified the topic sentence of the paragraph well "the topic sentence of the paragraph is also correct because it describes the topic of the paragraph perfectly, but I think it would be nicer if the words "which is" from the sentence "the subject which is taught by Maam Rita Inderawati" are omitted". Second, the student identified the supporting sentence of the paragraph well "Firstly, the title is written correctly because it tells the main contents of the paragraph well. The topic sentence of the paragraph is also correct because it describes the topic of the paragraph perfectly, but I think it would be nicer if the words "which is" from the sentence "the subject which is taught by Maam Rita Inderawati" are omitted. The next is controlling idea, it is written very well and does not need any correction". The next aspect is the concluding sentence, the concluding sentence is good because it begins with an appropriate end of paragraph signal. The concluding sentence has also mentioned the things that had been explained in advance. Then, the paragraph has no unclear sentence. After that, the aspect of the unity of this paragraph is written very well because the paragraph focuses on one main idea and does not go out of the track. Next, the paragraph has a good coherence because the paragraph consists of many transition signals. Finally, the last aspect is the grammatical and mechanics, there are no mistakes found regarding the spelling, punctuation or capitalization. Third, the student identified the concluding sentence of the paragraph well "the concluding sentence is good because it begins with an appropriate end of paragraph signal. The concluding sentence has also mentioned the things that had been explained in advance". Fourth and fifth, the student identified the unity and the coherence of the paragraph well "the aspect of the unity of this paragraph is written very well because the paragraph focuses on one main idea and does not go out of the track. The paragraph has a good coherence because the paragraph consists of many transition signals".

After the writer got the results for each score, then the writer drew the percentage from those results. The percentage of those results can be seen in this following table: 
Table 7

The Percentage of Each Score

\begin{tabular}{|l|l|}
\hline Score & Percentage \\
\hline Score 5 (very good) & $40 \times 100: 48=83.33 \%$ \\
\hline Score 4 (good) & $5 \times 100: 48=10.41 \%$ \\
\hline Score 3 (average) & $3 \times 100: 48=6.25 \%$ \\
\hline Total & $\mathbf{1 0 0 \%}$ \\
\hline
\end{tabular}

Briefly, the writer could conclude that from the students" comments on Facebook there are three categories of how well did the students identify the characteristics of a good paragraph, they are: 83.33 $\%$ students identified the characteristics of a good paragraph in very good level, $10.41 \%$ students identified the characteristics of a good paragraph in good level and $6.25 \%$ students identified the characteristics of a good paragraph in average level from the total $100 \%$ students.

Table 8

The Final Score of Students" Comments

\begin{tabular}{|c|c|c|c|}
\hline & & & $\mathrm{X}$ \\
\hline Q1 & Very Good (9-11) & 9 & 10 \\
\cline { 3 - 3 } & & 10 & \\
\cline { 3 - 3 } & & 11 & \\
\hline Q2 & Rater 1 & 15.86 & \multirow{2}{*}{15.56} \\
\cline { 2 - 3 } & Rater 2 & 15.25 & \\
\hline Q3 & Very Good & 5 & \multirow{2}{*}{4} \\
\cline { 2 - 3 } & Good & 4 & \\
\cline { 2 - 3 } & Average & 3 & \\
\hline & & & 9.85 \\
\hline
\end{tabular}

Overall, from the writer's results obtained from those three research questions by using Microsoft Excel 2010, the final score of students" comments was 9.85. Based on the scoring scale of an academic paragraph writing, score 9.85 was included into an average category with the scoring scale $7-12$. It could be concluded that the students' comments in Writing II subject with RI 2015 were average.

\section{DISCUSSION}

There are some points to be discussed based on the findings above. Based on the analysis process there were 4 students giving 9 
responses, 38 students giving 10 responses and 6 students giving 11 responses. So, there were three scores: 9,10 and 11 . Then, from those three scores, the writer found the average score was 10 by calculated in Microsoft Excel 2010. Score 10 was included into a very good category with the range of score $9-11$.

Finally, the writer could conclude that the completeness of the comment of the 2013 students of English Education Study Program was very good. Next, the quality of the comments of the students using the rubric for academic paragraph writing was rated by two raters. Rater 1 found out that there were 2 students getting score 12, 1 student getting score 14, 3 students getting score 15, 2 students getting score 16, 6 students getting score 17, 10 students getting score 18 and 24 students getting score 19 from the total 48 students. Rater 2 found out that there were 1 student getting score 11,1 student getting score 12,1 student getting score 14, 4 students getting score 15, 3 students getting score 16, 4 students getting score 17, 11 students getting score 18 and 23 students getting score 19 from the total 48 students.

From the writer's results obtained by using Microsoft Excel 2010, the result from rater 1 showed the average score was 15.86 and from rater 2 showed the average score was 15.25. The average score from both raters showed the score was 15.56 . Score 15.56 was included into a good category with the scoring scale $13-18$. Finally, the writer could conclude that the quality of the comment of the 2013 students of English Education study program was good. Thirdly, the writer made the percentage of how well the students identified the characteristics of a good paragraph. There were 5 scores in the scoring system, they are: score 5 (very good), score 4 (good), score 3 (average), score 2 (bad) and score 1 (failed). The results of the analysis showed that there were 40 students getting score 5 (very good), 5 students getting score 4 (good) and 3 students getting score 3 (average). There was no result found for score 2 and score 1.

Then, the writer made the percentage of those results. According to findings above, the writer got the results $83.33 \%$ students who got score 5 identified the paragraph in very good level, $10.41 \%$ students who got score 4 identified the paragraph in a good level and $6.25 \%$ students who got score 3 identified the paragraph in average level from the total $100 \%$ students. Overall, from the writer"s results obtained from those three research questions by using Microsoft Excel 2010, the final score of students" comments was 9.85. Based on the scoring scale of an academic paragraph writing, score 9.85 was included into average 
category with the scoring scale $7-12$. It could be concluded that the students" comments in Writing II subject with Rita Inderawati 2015 was average. Those all results had been gotten by the writer from collecting all the comments from the students in the Facebook comment column. Facebook provides some features in it and it has benefit to help the students in learning activities. It is relevant to the statement of Wichadee (2013, p. 3), it would be beneficial to use Facebook as a platform for students to give and get feedback since it creates authentic language interaction, increases students" motivation and enhances their English learning achievement. Furthermore, Rambe (2010) also states that Facebook is a ubiquitous technology for social use by students rather than an academic networking platform for their courses. Finally, from those experts say above, it would be beneficial if Facebook can be made as a medium in teaching and learning activities.

Based on the analysis results of research question number one, many students did not fulfill the eleven responses of a good comment. They mostly missed the eighth response suggesting a way to improve any unclear sentence. Only 6 students fulfilled it completely with all the eleven responses. For research question number two, the quality of the comments from the students was good with the final score was 15.56, means it was in a good category, with the scoring scale $13-18$. Then, for research question number three the writer did not find any scoring category for failed and bad. The students identified the characteristics of a good paragraph mostly in very good category with the total 40 students in it. Furthermore, the students had commented in Facebook comment column so that the writer can get the results above. Commenting on Facebook is good for their learning process. In line with this, Cheung, et al (2011) had noted that while "commenting in their Facebook, the students developed confidence in writing and reading English and communicating with other users of Facebook". In addition, it also gives them an opportunity to enhance their knowledge about the text review. Through commenting, students can state their opinion, make an argument, thus it will lead them to write their own review text. Not only that, Harris (1997) also states that writing comments on students' papers is something of an art; it requires a little thought and practice for the comments to be effective-that is, both read and attended to. The comment column lets people comment on content on the site using their Facebook account. People can choose to share their comment activity with their friends (and friends of their friends) on Facebook as well. Not only that, Facebook also has a feature which has been well known as "group". This feature provides an unlimited number of users 
to join with a common interest, ground, or certain purposes. It is possible to set whether the group will be in public or close or secret, as well. Through the group, the users do not need to "befriend" other users. They can interact directly with the group. Facebook group, according to Hur (2011), has seven main functions: post, link, photo, video, doc (document), event, and group chat. The post can be used to announce, remind, or ask something. It can also be the place where materials are shared. The activities for the post might be a specific topic discussion, short story, or survey.

\section{CONCLUSION AND SUGGESTION}

Based on the findings analyzed in the previous chapter, there were three conclusions. First of all, the completeness of the 2013 students of English Education in giving comment in Facebook of group writing II with Rita Inderawati Palembang 2015 could be categorized into the very good category. Secondly, the quality of the comment of the 2013 students of English Education study program was good. Thirdly, the percentage of how well the students identified the characteristics of a good paragraph was divided into three categories based on the result from analysis process, they were: $83.33 \%$ students who got score 5 identified the characteristics of a good paragraph in very good level, $10.41 \%$ students who got score 4 identified the characteristics of a good paragraph in good level and $6.25 \%$ students who got score 3 identified the characteristics of a good paragraph in average level. It could be concluded that the students" comments in Writing II subject with Rita Inderawati 2015 were average.

Based on the conclusion above, the following are the suggestions. First of all, the result of this study is expected to help students in improving their writing skill. It can help students give comments based on the rubric. Students will be able to give comments in Facebook comment column based on the rubric, they will know the characteristics of a good comment, the quality of their comments will be good in that way, and they can identify the characteristics of a good paragraph well or even very good. Not only that, by using Facebook in the teaching and learning process, the writer also hope the students can learn more effectively in writing subject and finally their writing ability will increase through this way.

Secondly, the writer hopes to the lecturers by getting the results of this study will help the lecturers to be successful in language teaching and learning activities for writing subject in the future especially by 
using Facebook and comments as the medium. Facebook is a good medium that can be used for teaching and learning activities. Facebook provides many important features in it and those all can be used by the lecturers to increase the students' attention and ability in learning activities especially for their writing II subject in the next day.

The last part is the suggestion for further researchers in the next day. The results of this study are also hoped to give more comprehensive information about Writing II subject to the other researchers in English Education Study Program at Faculty of Teacher Training and Education, Sriwijaya University. Besides, the writer also hopes to the other further researchers this study can give them the illustration of how writing II subject was going on in Sriwijaya University, they can do the same thing in other universities or in Sriwijaya University itself and they can correlate it with the students" writing achievement, or even in another subject not only writing on Facebook.

\section{REFERENCES}

Andrade, H. \& Du, Y. (2007). Student responses to criteria-referenced self-assessment. Assessment and Evaluation in Higher Education, 32(2), 159-181.

Cheung, C. M. K., Chiu, P. Y,. \& Lee, M. K. O. (2011). Online social networks: Why do students use facebook? Computers in Human Behavior. 27, 37-43.

Depdiknas. (1990). Sistem pendidikan nasional Peraturan Pemerintah No. 28. Jakarta, Indonesia: Depdiknas RI. Retrieved from http://www.dpr.go.id/

Fajri, M.H., Inderawati, R., \& Mirizon, S. (2015). The implementation of peer editing technique to improve students" writing achievement. Journal of English Literacy Education, 2(2), 48-57.

Falchikov, N. (2007). Rethinking assessment in higher education. London: Kogan Page.

Harmer, J. (2004). How to teach writing. Retrieved from http:/respository.upi.edu/operator/upload/t_bing_0604416_cha pter1.pdf

Harmer, J. (2007). The practice of English language teaching (4th ed.). Essex: Pearson Education Limited. 
Harris. (1997). Recommendations for writing comments on student papers. Retrieved from http://www.virtualsalt.com/comments.htm

Hattie, J. \& Timperley, H. (2007). The power of feedback. Review of Educational Research, 77(1), 81-112. doi: 10.3102/003465430298487. Retrieved from http://rer.sagepub.-com/content/77/1/81.full.pdf+html

Hur, G. (2011). Facebook: It's not all evil. Use the group feature! A paper presented at CAMTESOL 2011 State Conference. Retrieved from http://homepage.smc.edu/Liuroseanney/CATESOL\%202011/facebook.pdf

Hyland, K. (2007). Genre and second language writing. Ann Arbor, MI: The University of Michigan Press.

Inderawati, R. (2015). Commenting on the peer comment for single academic paragraph writing. Retrieved from https://www.facebook.com/groups-/539438949492702/?ref=bookmarks

Inderawati, R. (2016). A reflection on peer comment strategy in facebook for ELT. Retrieved from http://www.conference.pixel-online.net.

McMillan, J. H., \& Hearn, J. (2008). Student self-assessment: The key to stronger students' motivation and higher achievement. Retrieved from http://files.eric.ed.gov/fulltext-/EJ815370.pdf

Mertler, A. C. (2001). Practical assessment, research and evaluation: Designing scoring rubrics for your classroom. Retrieved from http://pareonline.-net/getvn.asp?v=7\&n=25

Oshima, A., \& Hogue, A. (1999). Writing academic English (3 ${ }^{\text {rd }}$ ed.). New York, NY: Adison-Wesley Longman.

Phelan, C., \& Wren, J. (2005). Exploring reliability in academic assessment. Retrieved from https://www.uni.edu/chfasoa/reliabilityandvalidity.htm

Rambe, P. (2010). Cited in Rambe, P. (2012). Critical discourse analysis of collaborative engagement in facebook postings. Australasian Journal of Educational Technology, 28, 295-314.

Rambe, P. (2012). Critical discourse analysis of collaborative engagement in facebook postings. Australasian Journal of Educational Technology, 28, 295-314. 
Spring (1999). Academic studies English; Writing longer essays. Retrieved from

http://www.en.copian.ca/library/learning/academic/english/wr iting/essaylng/module10.p $\underline{\mathrm{df}}$

Subandowo, D. (2013). Grammatical error analysis of student's comment writing based on facebook game in English intensive class of STAIN Jurai Siwo Metro. (Unpublished graduate thesis) STAIN Jurai Siwo Metro, Lampung.

Wichadee, S. (2013). Peer feedback on facebook: The use of social networking websites to develop writing ability of undergraduate students. Turkish Online Journal of Distance Education-TOJDE, 14(4), 1-13.

Winter, T. (1999). Academic studies English; Writing paragraphs and the writing process.

The National Adult Literacy, 2, 1-28. 